\title{
Insulin-like Growth Factor 1 (IGF-1) measurements recorded in the OZGROW database and their relation to growth response in children currently being treated with growth hormone
}

\author{
lan Hughes ${ }^{1 *}$, Mark Harris ${ }^{2}$, Andrew Cotterill ${ }^{2}$
}

From 8th APPES Biennial Scientific Meeting

Darwin, Australia. 29 October - 1 November 2014

\begin{abstract}
Aims
IGF-1 is produced in a GH dependent fashion and measurement of IGF-1 has become increasingly common for both diagnosis of $\mathrm{GH}$ deficiency and to guide $\mathrm{GH}$ therapy. The OZGROW database records the results of IGF-1 tests performed on patients receiving $\mathrm{GH}$ or being assessed for $\mathrm{GH}$ treatment. The OZGROW database was used to determine the extent to which IGF-1 testing is performed in this population and to assess the relationship between IGF-1 levels and growth rate.
\end{abstract}

\section{Methods}

Records were obtained for children entering the OZGROW database since 2009 and who were currently receiving $\mathrm{GH}$. Number of patients, visits, and frequency of IGF-1 tests was determined. The nature of IGF-1 tests, such as the units used and whether a reference range was provided was noted. Patients with at least one IGF-1 test result were selected for further analysis. IGF1 results were standardized (where a reference range was available) by expressing them as a \% of the reference range. $x \%=((x-L) /(U-L))$, where $x$ is the test result and $U$ and $L$ are the upper and lower values of the reference range. Growth was measured as either growth velocity $(\mathrm{GV}, \mathrm{cm} /$ year) or height SDS/Year over either a 6 month $(+/-10$ weeks but adjusted to $6 \mathrm{~m})$ or 1 year (+/-13weeks adjusted to 1y). Regressions (coefficient $=\mathrm{b}$ ) and correlations $(\mathrm{r})$ were performed.

Mater Research Institute, The University of Queensland, South Brisbane, QLD, Australia

Full list of author information is available at the end of the article

\section{Results}

829 patients were assessed representing 7573 clinic visits. 577 (69\%) did not have any IGF-1 tests recorded. $25 \%$ had one test recorded, $4 \%$ had two tests, and $1 \%$ had three tests. Another 21 IGF-1 tests were noted but not used in analyses as no reference range was given. Units used were $\mathrm{nmol} / \mathrm{L}, \mathrm{mmol} / \mathrm{L}, \mathrm{U} / \mathrm{ml}, \mathrm{ug} / \mathrm{L}, \mathrm{mg} / \mathrm{l}$, and "other". 11 results had a reference range but no units. Overall a moderate but significant relationship was found between IGF-1\% and growth: 6month GV- b=0.014cm/y/\%IGF-1, $\mathrm{r}=0.16$, $\mathrm{P}=0.01 ; 6$ month SDS $/ \mathrm{y}-\mathrm{b}=0.005 \mathrm{dSDS} / \mathrm{y} / \% \mathrm{IGF}-1, \mathrm{r}=0.31$, $\mathrm{P}<0.001$. 1Y GV $-\mathrm{b}=0.010, \mathrm{r}=0.14, \mathrm{P}=0.03 ; 1 \mathrm{Y} \mathrm{SDS} / \mathrm{y}-$ $\mathrm{b}=0.003, \mathrm{r}=0.31, \mathrm{P}<0.001$. More detailed analyses stratified by indication and gender will be presented.

\section{Discussion and conclusions}

IGF-1 has been recommended to titrate $\mathrm{GH}$ dose. We found significant variation between IGF-1\% and growth response although the correlation was significant. There was also great variation in measurement units used and references ranges stated. Further analyses will focus on the relationship between $\mathrm{GH}$ dose and IGF-1\% to help fully elucidate the value of IGF-1 testing in GH treatment.

\section{Authors' details}

${ }^{1}$ Mater Research Institute, The University of Queensland, South Brisbane, QLD, Australia. ${ }^{2}$ Mater Children's Hospital, South Brisbane, QLD, Australia.

Published: 28 April 2015

\section{doi:10.1186/1687-9856-2015-S1-P35}

Cite this article as: Hughes et al:: Insulin-like Growth Factor 1 (IGF-1) measurements recorded in the OZGROW database and their relation to growth response in children currently being treated with growth hormone. International Journal of Pediatric Endocrinology 2015 2015(Suppl 1):P38. 